\title{
Mold Attacks a Beating Heart
}

\author{
Thomas Weig ${ }^{\text {a }}$ Michael Irlbeck ${ }^{\mathrm{a}}$ Claus Neurohr ${ }^{\mathrm{d}}$ Hauke Winter ${ }^{\mathrm{b}}$ Rene Schramm ${ }^{\mathrm{c}}$ \\ Thomas Knösel ${ }^{\mathrm{e}}$ David Horst ${ }^{\mathrm{e}}$ \\ Departments of anaesthesiology, ${ }^{b}$ Surgery, ${ }^{c}$ Cardiac Surgery and ${ }^{\mathrm{d}}$ Internal Medicine V, Division of Pulmonary Diseases, \\ and ${ }^{\mathrm{e}}$ Institute of Pathology, Ludwig Maximilians University, Munich, Germany
}

A 64-year-old man with a history of pulmonary fibrosis and right-sided single lung transplantation was admitted for left-sided pulmonary aspergillosis. Leftsided pneumonectomy was performed. A bronchopleural fistula developed and persisted despite prolonged combined antimycotic therapy, left-sided thoracoplasty and reduction of immunosuppressant therapy. Blood ELISA detected Aspergillus galactomannan antigen in 2 out of 27 measurements at a cut-off value of 0.5 Optical Density Index (ODI) and 0 out of 27 measurements at a cut-off value of 1.5. Cardiac functions were stable with absence of cardiac arrhythmia despite intermittent atrial fibrillation until the patient suddenly died from acute heart failure. The autopsy findings are shown in figure 1.

Prevalence rates of $4.5 \%$ of invasive aspergillosis after lung transplantation in non-cystic fibrosis patients have been reported. Mortality rates of invasive pulmonary aspergillosis in lung transplant recipients are as high as $81.9 \%$ [1].
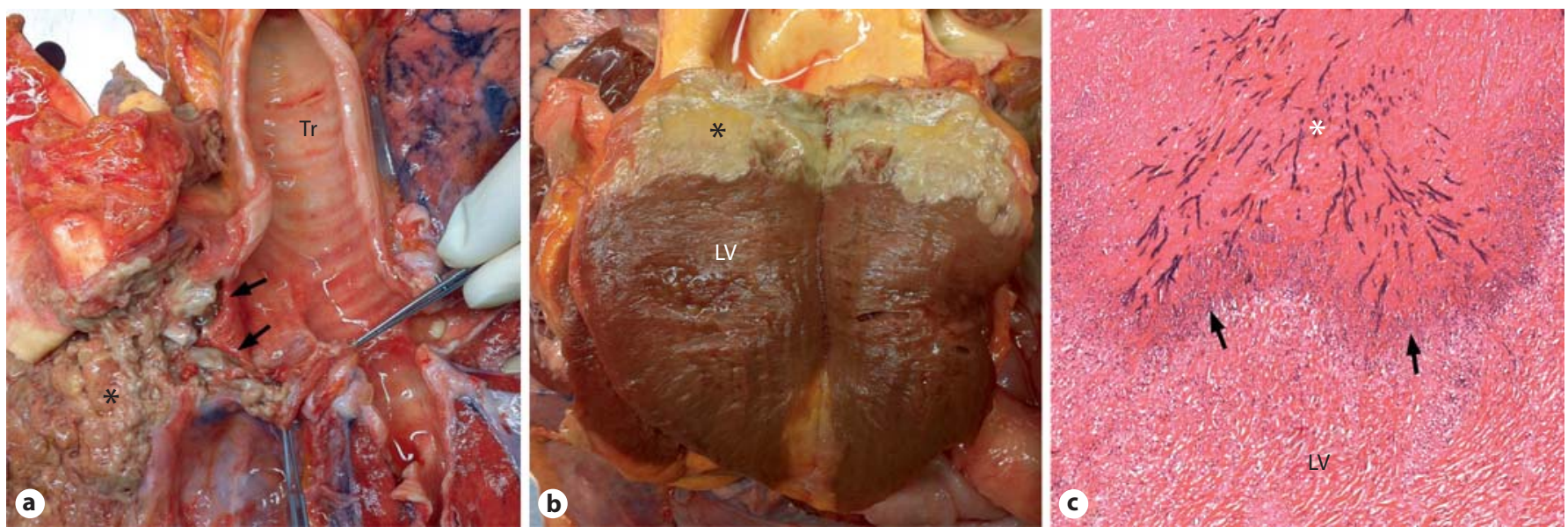

Fig. 1. Autopsy revealed significant insufficiency of the left primary bronchiolar stump (a, arrows), ending within necrotic debris of a pleuromediastinal aspergillosis (a, asterisk). The aspergillosis had invaded through the pericardium into the left heart ventricle (b, asterisk), which was confirmed by histology (c, asterisk). Only little inflammatory reaction surrounded the necrotic tissue (c, arrows). $\mathrm{Tr}=$ Trachea; $\mathrm{LV}=$ left anterior ventricle.

\section{KARGER}

Fax +4161306 1234 E-Mail karger@karger.ch www.karger.com (c) 2012 S. Karger AG, Basel

$0025-7931 / 13 / 0851-0064 \$ 38.00 / 0$

Accessible online at: www.karger.com/res
Dr. med. Thomas Weig

Department of Anaesthesiology, Ludwig-Maximilians-University Marchioninistrasse 15

DE-81377 Munich (Germany)

E-Mail thomas.weig@med.uni-muenchen.de 
Aspergillus galactomannan antigen ELISA has been reported to offer a sensitivity of 78 and $64 \%$ with a specificity of 81 and $95 \%$ at cut-off values of 0.5 and 1.5 ODI, respectively [2]. Nevertheless, Aspergillus galactomannan antigen can remain negative even in cases of massive invasive aspergillosis despite its generally high sensitivity.
1 Singh N, Husain S: Aspergillus infections after lung transplantation: clinical differences in type of transplant and implications for management. J Heart Lung Transplant 2003; 22:258-266.

2 Leeflang MM, Debets-Ossenkopp YJ, Visser $\mathrm{CE}$, et al: Galactomannan detection for invasive aspergillosis in immunocompromized patients. Cochrane Database Syst Rev 2008: CD007394. 